Detailed Chemical Kinetic Modeling of Surrogate Fuels for Gasoline and Application to an $\mathrm{HCCl}$ Engine

C. V. Naik, W. J. Pitz, M. Sjöberg, J. E. Dec, J. Orme, H. J. Curran, J. M. Simmie, C. K. Westbrook

January 10, 2005

2005 Joint Meeting of the U.S. Sections of The Combustion Institute

Philadelphia, PA, United States

March 20, 2005 through March 23, 2005 
This document was prepared as an account of work sponsored by an agency of the United States Government. Neither the United States Government nor the University of California nor any of their employees, makes any warranty, express or implied, or assumes any legal liability or responsibility for the accuracy, completeness, or usefulness of any information, apparatus, product, or process disclosed, or represents that its use would not infringe privately owned rights. Reference herein to any specific commercial product, process, or service by trade name, trademark, manufacturer, or otherwise, does not necessarily constitute or imply its endorsement, recommendation, or favoring by the United States Government or the University of California. The views and opinions of authors expressed herein do not necessarily state or reflect those of the United States Government or the University of California, and shall not be used for advertising or product endorsement purposes. 


\title{
Detailed Chemical Kinetic Modeling of Surrogate Fuels for Gasoline and Application to an HCCI Engine
}

\author{
Chitralkumar V. Naik ${ }^{1}$, William J. Pitz ${ }^{2}$ Magnus Sjöberg ${ }^{3}$, John E. Dec ${ }^{3}$, \\ John Orme ${ }^{4}$, Henry J. Curran ${ }^{4}$, John M. Simmie ${ }^{4}$, and Charles K. Westbrook ${ }^{2}$ \\ ${ }^{1}$ Colorado School of Mines, Golden, CO 80401 \\ ${ }^{2}$ Lawrence Livermore National Laboratory, Livermore, CA 94551 \\ ${ }^{3}$ Sandia National Laboratory, Livermore, CA 94551 \\ ${ }^{4}$ National University of Ireland, Galway, Ireland
}

\begin{abstract}
Gasoline consists of many different classes of hydrocarbons, such as paraffins, olefins, aromatics, and cycloalkanes. In this study, a surrogate gasoline reaction mechanism is developed, and it has one representative fuel constituent from each of these classes. These selected constituents are iso-octane, n-heptane, 1-pentene, toluene, and methyl-cyclohexane. The mechanism was developed in a step-wise fashion, adding submechanisms to treat each fuel component. Reactions important for low temperature oxidation $(<1000 \mathrm{~K})$ and cross-reactions among different fuels are incorporated into the mechanism. The mechanism consists of 1214 species and 5401 reactions. A single-zone engine model is used to evaluate how well the mechanism captures autoignition behavior for conditions corresponding to homogeneous charge compression ignition (HCCI) engine operation. Experimental data are available for both how the combustion phasing changes with fueling at a constant intake temperature, and also how the intake temperature has to be changed with pressure in order to maintain combustion phasing for a fixed equivalence ratio. Three different surrogate fuel mixtures are used for the modeling. Predictions are in reasonably good agreement with the engine data. In addition, the heat release rate is calculated and compared to the data from experiments. The model predicts less low-temperature heat release than that measured. It is found that the low temperature heat-release rate depends strongly on engine speed, reactions of $\mathrm{RO}_{2}+\mathrm{HO}_{2}$, fuel composition, and pressure boost.
\end{abstract}

\section{Introduction}

The homogeneous charge compression ignition (HCCI) combustion process is capable of providing both good fuel economy and very low NOx and particulate emissions. Therefore, substantial efforts are being made to develop HCCI as a high-efficiency alternative to sparkignited (SI) gasoline operation and as a low-emissions alternative to traditional diesel compression ignition (CI) combustion. However, several technical hurdles still hinder widespread application of HCCI. Among these, controlling the combustion phasing during changes to the engine load and speed continues to be a major issue. The time of ignition in an HCCI engine is controlled by the autoignition of the fuel. The fuel is premixed with air and this mixture autoignites due to compressive heating. The autoignition is dominated by the kinetics of the fuel. Therefore, it is most important to understand the fuel chemistry that governs the engine performance. The autoignition kinetics change with equivalence ratio of the supplied fuel-air mixture, speed of the engine, boost pressure, and intake temperature. A smooth performance of the engine demands that the ignition occurs at the correct crank angle. Too early ignition can advance the combustion to the point of excessive pressure-rise rates and knock. Too late ignition can lead to quenching of the combustion due to piston expansion. Since gasoline is widely available, it is an attractive fuel-candidate for use in HCCI engines.

The present study is motivated by the need to understand the autoignition kinetics of gasoline. Since gasoline consists of numerous components, it is not feasible to incorporate the chemistry of all the components in the modeling. Therefore, surrogate fuels that describe the behavior of gasoline are required. Surrogate fuels might also be helpful to identify how the currently available gasoline blends might be reformulated to better facilitate future implementation of HCCI in production engines.

The goals of this study are 1) propose surrogate fuel mixtures to represent ignition behavior of gasoline, 2) develop a detailed kinetic mechanism for oxidation of these fuels, and 3) validate the mechanism against experimental data from the Sandia HCCI engine.

\footnotetext{
* Corresponding author: pitz1@1lnl.gov

Proceedings of the Joint Meeting of the U.S. Sections of The Combustion Institute, March 2005
} 


\section{Surrogate fuel mixtures for gasoline}

Gasoline consists of hundreds of chemical species. The identity and amount of each species varies depending on date and geographical location where the gasoline was obtained. A chemical kinetic mechanism that would represent the oxidation of all these species with accompanying chemical reactions is intractable with current computational capabilities, chemical knowledge and manpower resources. These limitations require the use of surrogates for practical fuels like gasoline, diesel and aviation fuels. A surrogate fuel model consists of a small number of fuel components that can be used to represent the practical fuel and still predict desired characteristics of the practical fuel. In this study, we have chosen a fuel surrogate that has a single component to represent each class of hydrocarbons in gasoline so that the unique molecular structure of each class is represented. It is desired that this strategy will lead to reliable predictions of many of the combustion properties of the practical fuel. Gasoline consists of many different classes of hydrocarbons including $4-8 \%$ alkanes, $2-5 \%$ alkenes, $25-40 \%$ iso-alkanes, $3-7 \%$ cycloalkanes, $1-4 \%$ cycloalkenes, and $20-50 \%$ total aromatics by volume [1]. We have selected a representative fuel component for each class of hydrocarbons. We selected n-heptane to represent the n-alkane class, iso-octane to represent the iso-alkane class, methyl-cyclohexane to represent cycloalkane class, toluene to represent the aromatics class, and 1-pentene to represent the alkene class. Due to the small amount of cycloalkenes in gasoline, a representative fuel is not considered at this point to avoid the added complexity of the kinetic modeling.

Three surrogate fuel mixtures for gasoline are proposed. Their composition is shown in Table 1. Molar composition and octane numbers of the proposed surrogate fuel mixtures for gasoline.

. The mixture 1 consists of five components to represent the different classes of hydrocarbons in gasoline. Its Research Octane Number (RON) and Motor Octane Number (MON) are slightly higher than that of a typical gasoline of 90.8 and 83.4 respectively. The calculated linear octane numbers are based on linear mixing using the octane number of the neat fuel component (sum of fuel mole fraction $\mathrm{x}$ octane number of neat fuel). Blend octane numbers for the neat fuel are based on measurements by blending 20 vol. \% of the specific hydrocarbon in $80 \mathrm{vol}$. \% of a $60 / 40$ iso-octane/nheptane mixture [2]. The octane numbers for surrogate fuel mixtures based on blend octane numbers are an alternative indicator of the autoignition properties. Mixture 2 and 3 were developed to have the RON and MON closer to that of a typical gasoline. For these mixtures, the amounts of n-heptane and methylcyclohexane $(\mathrm{MCH})$ are in different quantities, and 1-pentene is not included.

\section{Mechanism development}

Detailed kinetic mechanisms were used to represent each component in the surrogate fuel mixture. The mechanism was built in a step-wise fashion with species and reactions needed to address each fuel component added in sequence. The mechanisms for primary reference fuels (PRF) iso-octane and n-heptane were used as a starting point $[3,4,5]$. This mechanism already includes the reactions of 1-pentene. Reactions and species needed to address the oxidation of toluene where added from a mechanism developed by Pitz et al. [6]. The submechanism for methylcyclohexane $(\mathrm{MCH})$ was obtained from a recently developed mechanism by Orme et al. [7]. This mechanism addresses the high temperature, but not the low temperature, oxidation of $\mathrm{MCH}$.

In this work, low temperature kinetics for oxidation of $\mathrm{MCH}$ has been developed and incorporated in the mechanism. This mechanism considers the low temperature kinetics scheme given as,

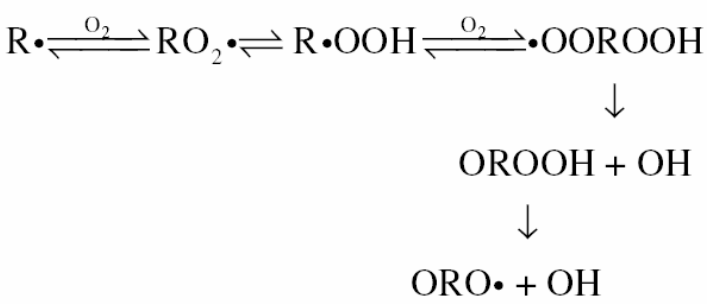

Here $\mathrm{R} \bullet$ is the parent radical from $\mathrm{MCH}$. Additional reactions of $\mathrm{RO}_{2} \bullet$ and alkoxy species are also included. Due to space constraint, this mechanism is not described in detail.

Cross-reactions of the species in the base PRF mechanism and the sub-mechanisms for toluene and $\mathrm{MCH}$ were incorporated. These reactions mainly consist of the hydrogen abstraction reactions. For example, phenyl is a major radical produced from the oxidation of toluene. This phenyl radical can also abstract hydrogen from the other fuels and their products. All of these reactions were incorporated in the mechanism developed. In addition, reactions for abstraction by $\mathrm{RO}_{2} \bullet$ radicals from parent fuels were included, since they are very important for low temperature oxidation and autoignition kinetics. Also, the reactions of $\mathrm{RO}_{2} \bullet+\mathrm{RO}_{2} \bullet$ (including various $\mathrm{R}$ groups) were included in the mechanism. Olefins and allylic radicals can be produced in high amounts during the oxidation of alkanes at low temperatures (below $1000 \mathrm{~K}$ ). Therefore, the abstraction reactions by allylic radicals from olefins were included in the mechanism. The rate coefficients assignments for these reactions were based on rate rules developed by Curran et al. [3, 5]. Rate rules were developed for the reactions where they were not available. These rate rules are shown in Table 2. 
Table 1. Molar composition and octane numbers of the proposed surrogate fuel mixtures for gasoline.

\begin{tabular}{|l|c|c|c|}
\hline \% molar composition & Mixture 1 & Mixture 2 & Mixture 3 \\
\hline iso-Octane & 60 & 40 & 40 \\
n-Heptane & 8 & 10 & 20 \\
Toluene & 20 & 10 & 10 \\
Methyl cyclohexane & 8 & 40 & 30 \\
1-Pentene & 4 & 0 & 0 \\
\hline RON (linear) & 93.7 & 81.7 & 83.7 \\
MON (linear) & 90.6 & 79.3 & 79.8 \\
\hline RON (blend) & 99.2 & 94 & 87.6 \\
MON (blend) & 94.5 & 84.8 & 82 \\
\hline
\end{tabular}

Table 2. Rate coefficients for reactions in the mechanism that were not available from Curran et al.

\begin{tabular}{|c|c|c|c|}
\hline & A & $\mathbf{n}$ & Ea \\
\hline \multicolumn{4}{|l|}{ Abstraction by primary allylic radical from olefin } \\
\hline Olefin $+\mathrm{C}_{5} \mathrm{H}_{7}=$ Alkenyl $+\mathrm{C}_{5} \mathrm{H}_{8}$ & $1.00 \mathrm{E}+11$ & 0 & 16000 \\
\hline Olefin $+\mathrm{C}_{5} \mathrm{H}_{9}=$ Alkenyl $+\mathrm{C}_{5} \mathrm{H}_{10}$ & $1.00 \mathrm{E}+11$ & 0 & 16000 \\
\hline \multicolumn{4}{|c|}{ Abstraction by secondary allylic radical from olefin } \\
\hline Olefin $+\mathrm{C}_{2} \mathrm{H}_{3} \mathrm{CHCHO}=$ Alkenyl $+\mathrm{C}_{2} \mathrm{H}_{3} \mathrm{CH}_{2} \mathrm{CHO}$ & $2.86 \mathrm{E}+10$ & 0 & 18000 \\
\hline \multicolumn{4}{|l|}{ Abstraction by benzyl radical from olefin } \\
\hline Olefin $+\mathrm{C}_{6} \mathrm{H}_{5} \mathrm{CH}_{2}=$ Alkenyl $+\mathrm{C}_{6} \mathrm{H}_{5} \mathrm{CH}_{3}$ & $1.00 \mathrm{E}+11$ & 0 & 17000 \\
\hline \multicolumn{4}{|l|}{ Abstraction by generic $\mathrm{RO}_{2}$ radical } \\
\hline $\mathrm{RO}_{2}+\mathrm{CH}_{2} \mathrm{O}=\mathrm{ROOH}+\mathrm{HCO}$ & 1.00E+12 & 0 & 9000 \\
\hline $\mathrm{RO}_{2}+\mathrm{C}_{6} \mathrm{H}_{5} \mathrm{CHO}=\mathrm{ROOH}+\mathrm{C}_{6} \mathrm{H}_{5} \mathrm{C} \cdot \mathrm{O}$ & $3.00 \mathrm{E}+12$ & 0 & 9000 \\
\hline $\mathrm{RO}_{2}+\mathrm{H}_{2} \mathrm{O}_{2}=\mathrm{ROOH}+\mathrm{HO}_{2}$ & $1.32 \mathrm{E}+04$ & 2.5 & 9560 \\
\hline
\end{tabular}

\section{Modeling an HCCI engine}

The experiments on HCCI engine were performed at Sandia National Laboratories, Livermore, California. The setup is described in previous publications [8, 9]. In brief, the engine is operated with a lean well-mixed charge of fuel and air. For these tests, the equivalence ratio $(\phi)$ ranged from 0.08 to 0.30 . An alternate firing method (fire19/1) was used to keep the heat transfer and residuals constant for all the data points, as described in Refs. [9] and [10]. The amount of residuals in the engines is less than 5 vol. $\%$ and consists mainly of combustion products, $\mathrm{CO}_{2}, \mathrm{H}_{2} \mathrm{O}, \mathrm{O}_{2}$, and $\mathrm{N}_{2}$. Therefore, residuals are not expected to have significant impact on the data, as shown in Ref. [10].

The engine has an effective compression ratio (CR) of 16.7:1, based on Wave-modeling [10]. This is the CR used for the modeling in the current work as well. Due to the large size of the mechanism (1328 species and 5695 reactions), long computational times are required when a multidimensional reacting-flow computer program is used to model the in-cylinder processes of HCCI. Since, the focus is to understand the ignition kinetics of the fuel, a single zone, adiabatic, and well-mixed engine model as implemented in Senkin (as used in [9]) is used for the modeling. Since the model is adiabatic, absolute comparison with the data is not possible. However, the constant heat losses with changes in equivalence ratio (due to $19 / 1$ firing method) in the experiments make the qualitative comparison possible. There are three types of data used to compare with model predictions, described below.

(1) Combustion phasing vs. fuel equivalence ratio

Combustion phasing in the HCCI engine changes with a change in the fuel/air equivalence ratio. Dec and Sjöberg [9] measured the crank angle $\left({ }^{\circ} \mathrm{CA}\right)$ for $10 \%$ of cumulative heat release (also referred to as $10 \%$ burn) at different equivalence ratios at $1200 \mathrm{rpm}$ and constant intake pressure of $100 \mathrm{kPa}$ and temperature of $409 \mathrm{~K}$. For a comparison of the modeling calculations with the experiments, the bottom dead temperature $\left(\mathrm{T}_{\mathrm{BDC}}\right)$ in the model was adjusted to match the experimental $10 \%$-burn phasing at an equivalence ratio of 0.16 for all three surrogate-fuel mixtures. This $\mathrm{T}_{\mathrm{BDC}}$ was then kept constant for all other $\phi$ in the calculations for that surrogate-fuel mixture. The comparison of the data and predictions for all surrogate mixtures is shown in Fig. 1.

As seen in the figure, the data show about $1{ }^{\circ} \mathrm{CA}$ delay in the $10 \%$-burn phasing as $\phi$ is increased from 0.08 to 0.3 . The predictions using the Mixture 1 and 2 are very similar to each other. The predictions for the Mixture 3 are in slightly better agreement with the data. At first, the behavior in Fig. 1 seems unexpected. As the fuel becomes more fuel-rich, the volumetric heat release increases, the 
peak cylinder temperature rises, and the combustion rate after autoignition will be faster. This would tend to shift the $50 \%$-burn point earlier in the cycle. However, the autoignition characteristics of the fuel/air mixture are not necessarily affected in the same manner. Fig. 1 shows that the phasing of the $10 \%$ burn point is retarded as the mixture becomes more fuel-rich. At this low burn point, the autoignition processes are dominant, and the increase heating value of the fuel has little effect. Thus, the enhancement of the autoignition with $\phi$ is not sufficient to compensate for the reduced compressional heating due to the decrease in specific heat ratio $\left(\gamma=\mathrm{C}_{\mathrm{p}} / \mathrm{C}_{\mathrm{v}}\right)$ from increased fuel loading. The model captures this experimental observation.

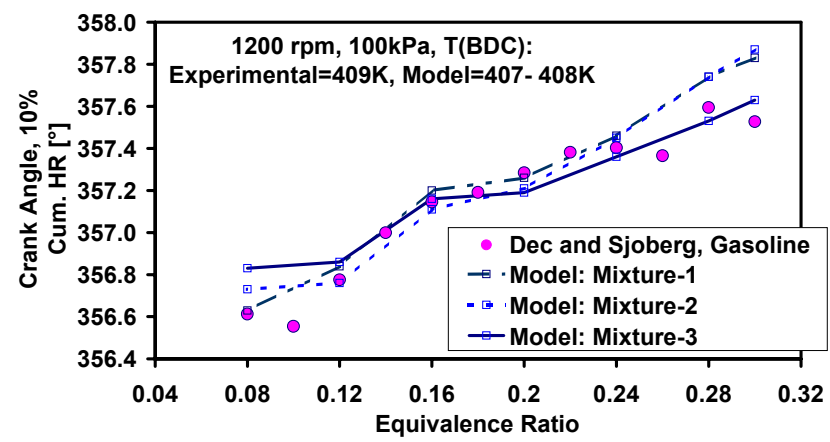

Fig. 1. Comparison of the predicted and measured crank angle for $10 \%$ burn at different equivalence ratios at constant intake pressure of $100 \mathrm{kPa}$ and temperature. For qualitative comparison, $\mathrm{T}_{\mathrm{BDC}}$ in modeling is adjusted to match that measured at $\phi$ of 0.16 .

\section{(2) Change in $T_{\mathrm{BDC}}$ with intake pressure}

The change in $\mathrm{T}_{\mathrm{BDC}}$ was measured with the change in intake pressures to maintain constant $50 \%$ burn point at the top dead center (TDC). These measurements were performed using a constant equivalence ratio of 0.2 at an engine speed of $1200 \mathrm{rpm}$. Higher intake pressures (boost) increase both the autoignition rate and the overall reaction rate, and $\mathrm{T}_{\mathrm{BDC}}$ needs to be lowered to maintain the $50 \%$ burn point at TDC (Fig. 2). At $1200 \mathrm{rpm}$, the experimental data show an even sharper decrease in $\mathrm{T}_{\mathrm{BDC}}$ for intake pressures above $170 \mathrm{kPa}$. This behavior is due to an observed increase in low temperature heat release (discussed later). The predictions show a smaller decrease in $\mathrm{T}_{\mathrm{BDC}}$ with increase in intake pressure than the measurements. In addition, predictions do not capture the more sharp decrease in $\mathrm{T}_{\mathrm{BDC}}$ above $170 \mathrm{kPa}$ due to low temperature heat release. The predicted behavior has little dependence on the choice of surrogate mixture.

Predictions for lower engine speed are also shown in Fig. 2. We can see that the model predicts the more sharp decrease in $\mathrm{T}_{\mathrm{BDC}}$ at boost pressures from 170 to $190 \mathrm{kPa}$ at $600 \mathrm{rpm}$. This predicted behavior is more pronounced for $300 \mathrm{rpm}$ engine speed. Therefore, the model does capture the observed trend at lower engine speed where there is more time for low temperature chemistry to occur.

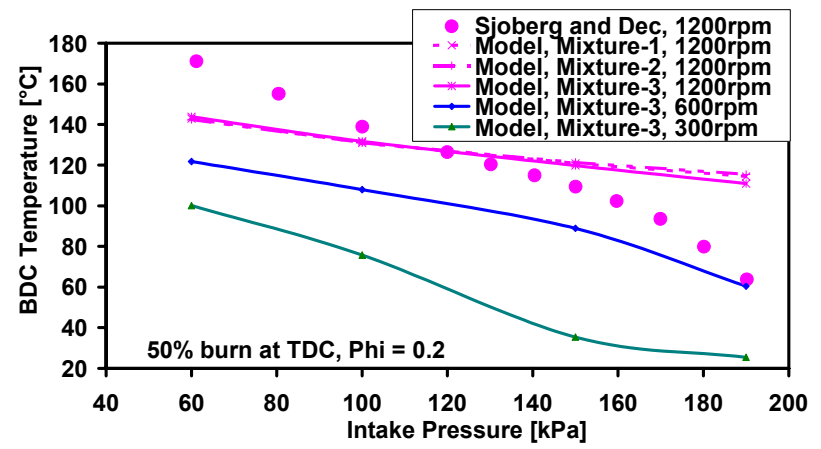

Fig. 2. Comparison of the measured and predicted $T_{B D C}$ at various intake pressures to maintain $50 \%$ burn at TDC for speed of $1200 \mathrm{rpm}$. Predictions using Mixture 3 at lower speeds of $600 \mathrm{rpm}$ and $300 \mathrm{rpm}$ are also shown.

\section{(3) Heat release rate vs. crank angle}

The heat release rate is shown as a function of crank angle in Fig. 3. Heat release rate (Joule/Crank angle) shows a large peak near TDC (for 50\% burn at TDC). At $190 \mathrm{kPa}$ intake pressure and $1200 \mathrm{rpm}$, gasoline shows low temperature heat release $(\phi=0.2)$. We can see a small peak near $346{ }^{\circ} \mathrm{CA}$ due to this early heat release. The predictions are shown using Mixture 3 (Fig. 3a) and Mixture 1 (Fig. 3b). We can see that the predictions (labeled $1200 \mathrm{rpm}$ ) do not show the early heat release as observed experimentally. But for lower engine speeds, predictions using the Mixture 3 show early heat release (Fig. 3a). The magnitude of this heat release rate is higher for $300 \mathrm{rpm}$ than that at $600 \mathrm{rpm}$. These observations are also consistent with those seen for $\mathrm{T}_{\mathrm{BDC}}$ vs. $\mathrm{P}_{\text {in }}$ (Fig. 2). These predicted results show the sensitivity of the model to engine speed.

As seen in Fig. $3 b$, the predicted early heat release rate of Mixture 1 is smaller than that of Mixture 3, for 300 rpm case. This is due to the larger amount of $n$-heptane in Mixture 3, a fuel component that exhibits higher lowtemperature $(<1000 \quad \mathrm{~K})$ reactivity than the other components. In addition, the predicted early heat release rate shows sensitivity to the $\mathrm{RO}_{2} \bullet+\mathrm{HO}_{2}$ reactions. As seen in Fig. 3b, the heat release rate is higher when the rate coefficients are increased for these reactions by a factor of two. These reactions produce $\mathrm{ROOH}$ species that participate in chain branching at lower temperatures. 

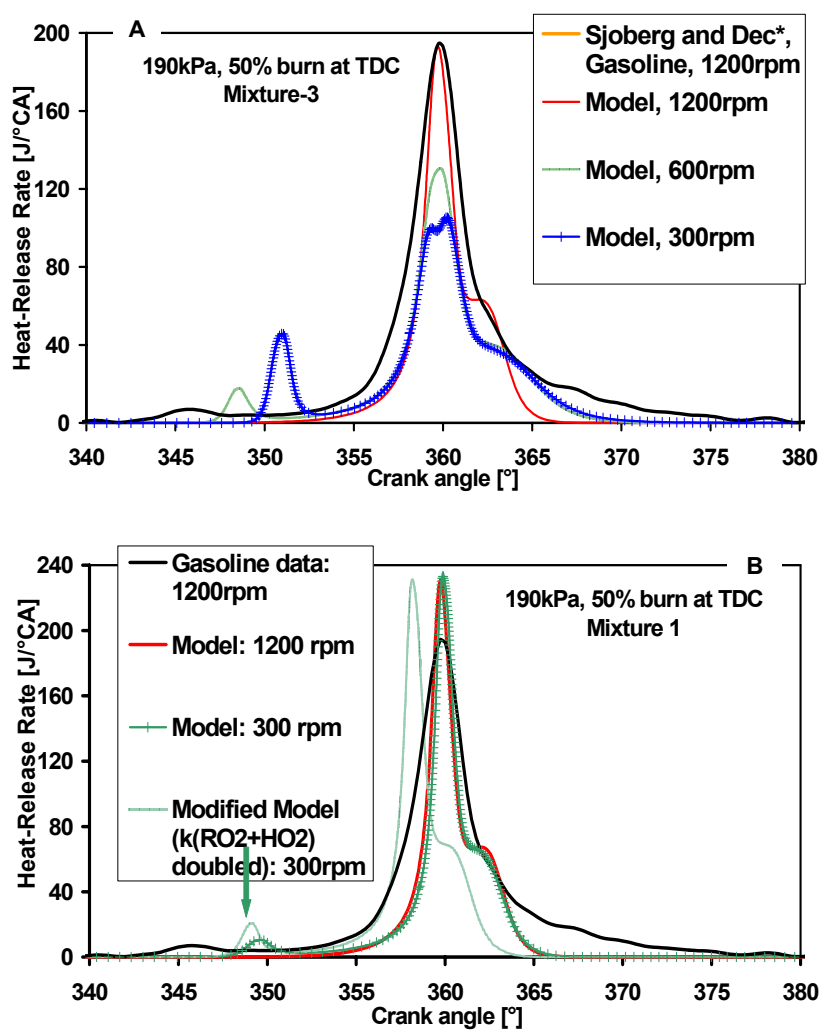

Fig. 3. Comparison of the measure heat release rate as a function of crank angle for $1200 \mathrm{rpm}$ using gasoline to that predicted using (a) the Mixture 3, and (b) the Mixture 1. Predictions at lower engine speeds are also shown.

\section{Results for $\mathrm{MCH}$}

Experimental data for neat $\mathrm{MCH}$ were obtained using the HCCI engine. Fig. 4 shows comparison of the predicted and measured change in bottom dead center $\left(\mathrm{T}_{\mathrm{BDC}}\right)$ with change in equivalence ratio to maintain the $50 \%$ burn point at the top dead center (TDC) at an intake pressure of $100 \mathrm{kPa}$ and $1200 \mathrm{rpm}$ engine speed. $\mathrm{T}_{\mathrm{BDC}}$ does not change significantly with change in fuel loading and our model captures this behavior of neat $\mathrm{MCH}$. Since heattransfer effects are neglected and a single zone Senkin program is used for modeling it is not possible to do quantitative comparison. In general, the predicted $\mathrm{T}_{\mathrm{BDC}}$ using the adiabatic model is approximately $15{ }^{\circ} \mathrm{C}$ higher than that observed in the HCCI engine. This suggests that the kinetics in the model are too slow. Fig. 5 shows a comparison of the predicted and measured $\mathrm{T}_{\mathrm{BDC}}$ at different boost pressures $\left(\mathrm{P}_{\text {in }}\right)$ to maintain $50 \%$ burn point at TDC at an equivalence ratio of 0.2 and $1200 \mathrm{rpm}$ engine speed. The predicted decrease in $\mathrm{T}_{\mathrm{BDC}}$ with increase in $\mathrm{P}_{\text {in }}$ for neat $\mathrm{MCH}$ fuel is less than that observed in the engine. This observation is similar to that seen in Fig. 2 for all surrogate fuel mixtures regardless the amount of $\mathrm{MCH}$ in mixtures.

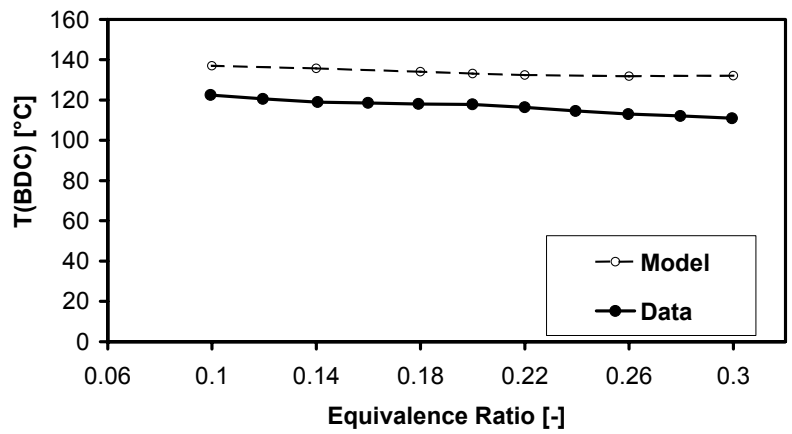

Fig. 4. Comparison of predicted and measured $\mathrm{T}_{\mathrm{BDC}}$ at different equivalence ratios for neat $\mathrm{MCH}$ fuel to maintain $50 \%$ burn point at TDC at intake pressure of $100 \mathrm{kPa}$ and $1200 \mathrm{rpm}$ engine speed.

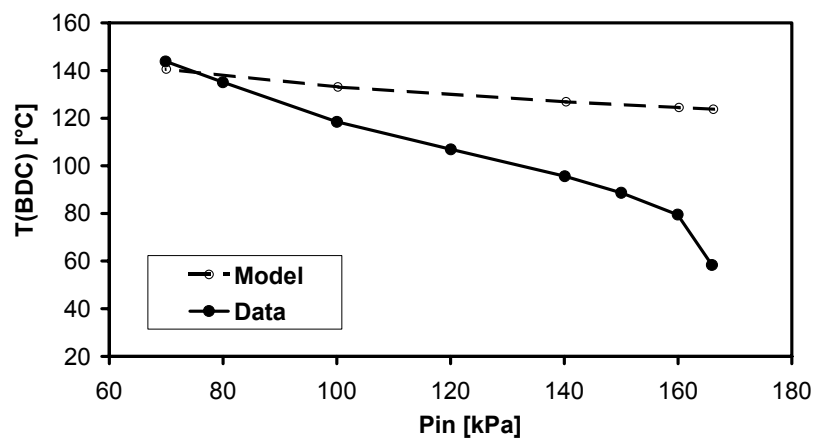

Fig. 5. Comparison of predicted and measured $\mathrm{T}_{\mathrm{BDC}}$ at different intake pressures for neat $\mathrm{MCH}$ fuel to maintain $50 \%$ burn point at TDC at an equivalence ratio of 0.2 and $1200 \mathrm{rpm}$ engine speed.

A possible explanation for the inability of the model to accurately predict the pressure dependence of the system is that the rate coefficients used are at their highpressure limit and described in modified Arrhenius form. Rate constant for chemically and thermally activated reactions of many smaller molecules are pressure dependent and may not be at the high-pressure limit under the conditions of HCCI engine (mainly at the beginning of the cycle). Since the pressure is changing rapidly in the engine, the pressure dependence of rate coefficients may influence the predictions.

\section{Shock Tube Comparisons}

Gauthier et al. [11] measured ignition delay times of surrogate fuel mixtures using reflected shocks. The measurements were performed in the range of $850-1280 \mathrm{~K}$ and 15-60 atm. They used two surrogate mixtures of three components (Liquid volume percent of isooctane/toluene/n-heptane: 63/20/17 for Surrogate A and $69 / 14 / 17$ for Surrogate B). The current model was validated against these ignition time data for both surrogate mixtures. Shock program from Chemkin 3.6.2 [12] package was used for simulations. In Fig. 6, we show 
the experimental data scaled to $55 \mathrm{~atm}$ using the measured pressure dependence of $\mathrm{P}^{-0.96}$ for the surrogate mixture $\mathrm{A}$, and $\mathrm{P}^{-0.83}$ for the surrogate mixture $\mathrm{B}$ [11]. As seen in Fig. 6 , the predicted ignition time captures the temperature dependence of the ignition time. But the predicted ignition kinetics are slightly slower than that observed experimentally.

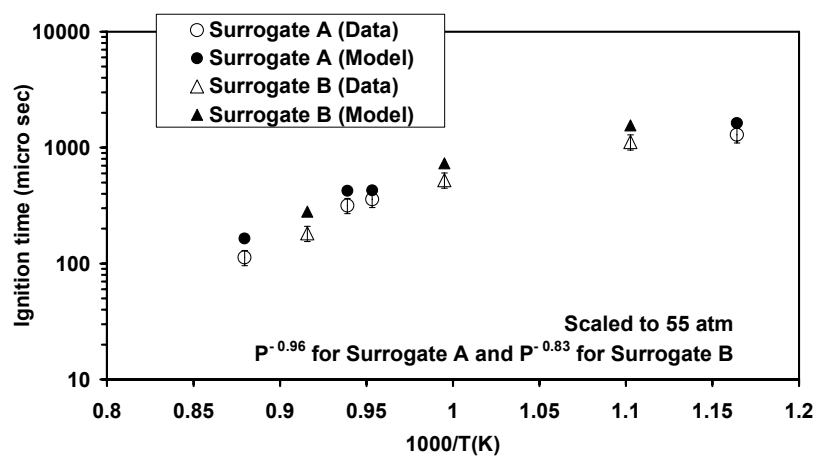

Fig. 6. Comparison of the predictions to the measured ignition time for surrogate fuel mixtures A and B suggested by Gauthier et al. [11] (see text).

This observation is consistent with that seen earlier in this paper that at higher intake pressures, the predicted kinetics are slower than that experimentally observed in the $\mathrm{HCCI}$ engine (i.e., a higher $\mathrm{T}_{\mathrm{BDC}}$ was required for the model to obtain the same $50 \%$ burn phasing).

\section{Future work}

The reactions that control the pressure dependence observed in Figs. 2 and 5 need to be identified. Then the rate constants and product channels of these reactions can be further investigated and adjustments made. This may lead to improved predictions by the model. It is important to incorporate the pressure dependence of rate coefficients for chemically activated reactions. Typically, near atmospheric pressure, the rate constants for chemically activated reactions of $\mathrm{C}_{1}$ to $\mathrm{C}_{3}$ hydrocarbons are in the falloff region. [13]. These pressure dependent rate coefficients can be represented using Chebyshev polynomials [14] over broad range of temperatures and pressures. This form for representing $\mathrm{k}(\mathrm{T}, \mathrm{P})$ has also been incorporated in Chemkin 3.6.2 software.

Another important step is to incorporate the heat losses in the model. This will allow better quantitative comparison with the experimental data.

\section{Acknowledgments}

This work was supported by the U.S. Department of Energy, Office of Freedom CAR and Vehicle Technologies and under the auspices of the U.S. Department of Energy by University of California Lawrence Livermore National Laboratory under contract
No. W-7405-Eng-48. The authors thank program managers Stephen Goguen and Gurpreet Singh for their support of this work.

\section{References}

[1] Http://www.atsdr.cdc.gov/toxprofiles/tp72-c3.pdf, Agency for Toxic Substances and Disease Registry, December 4, 2004.

[2] Http://www.refiningonline.com/engelhardkb/, December 4, 2004.

[3] H. J. Curran, P. Gaffuri, W. J. Pitz and C. K. Westbrook, Combust. Flame 129 (2002) 253-280.

[4]Http://www.cms.llnl.gov/combustion /combustion_home.html, LLNL Combustion Mechanisms, December 2004.

[5] H. J. Curran, P. Gaffuri, W. J. Pitz and C. K. Westbrook, Combust. Flame 114 (1998) 149-177.

[6] W. J. Pitz, R. Seiser, J. W. Bozzelli, K. Seshadri, C.-J. Chen, I. Da Costa, R. Fournet, F. Billaud, F. Battin-Leclerc and C. K. Westbrook, "Chemical Kinetic Study of Toluene Oxidation under Premixed and Nonpremixed Conditions", UCRL-CONF-201575 (2003).

[7] J. Orme, J. M. Simmie and H. J. Curran, "A Shock

Tube Study of Methylcyclohexane Oxidation,"

Proceedings of the European Combustion Meeting,

Orleans, France, 2003.

[8] M. Sjöberg and J. E. Dec, "Combined Effects of Fueltype and Engine Speed on Intake Temperature

Requirements and Completeness of Bulk-gas Reactions for HCCI Combustion", SAE 2003-01-3173 (2003).

[9] J. E. Dec and M. Sjöberg, "Isolating the Effects of Fuel Chemistry on Combustion Phasing in an HCCI Engine and the Potential of Fuel Stratification for Ignition Control," SAE 2004-01-0557 (2004).

[10] M. Sjöberg and J. E. Dec, " An Investigation of the Relationship between Measured Intake Temperature, BDC Temperature, and Combustion Phasing for Premixed and DI HCCI Engines", SAE 2004-01-1900 (2004).

[11] B. M. Gauthier, D. F. Davidson and R. K. Hanson, Combust. Flame 139 (2004) 300-311.

[12] R. J. Kee, F. M. Rupley, J. A. Miller, M. E. Coltrin, J. F. Grcar, E. Meeks, H. K. Moffat, A. E. Lutz, G. DixonLewis, M. D. Smooke, J. Warnatz, G. H. Evans, R. S. Larson, R. E. Mitchell, L. R. Petzold, W. C. Reynolds, M. Caracotsios, W. E. Steward, P. Glarborg, C. Wang and O. Adigun, Chemkin Collection, Release 3.6, San Diego, CA, Reaction Design, Inc., 2000.

[13] C. V. Naik, "Modeling the Low to Intermediate Temperature Oxidation and Pyrolysis of Hydrocarbons," PhD Thesis, Chemical Engineering, Colorado School of Mines, 2004.

[14] C. Naik, H.-H. Carstensen and A. M. Dean, "Reaction Rate Representation Using Chebyshev Polynomials," In WSS 2002 Spring Meeting of the Combustion Institute, San Diego, CA, 2002. 